\title{
High prevalence of HIV and sexually transmitted infections among male sex workers in Abidjan, Côte d'lvoire: need for services tailored to their needs
}

\author{
Bea Vuylsteke, ${ }^{1}$ Gisèle Semde, ${ }^{2}$ Lazare Sika, ${ }^{3}$ Tania Crucitti, ${ }^{1}$ Virginie Ettiegne Traore, \\ Anne Buve, ${ }^{1}$ Marie Laga ${ }^{1}$
}

${ }^{1}$ Institute of Tropical Medicine, Antwerp, Belgium

${ }^{2} \mathrm{FHI}$, Abidjan, Côte d'Ivoire

${ }^{3}$ National Institute of Statistics and Applied Economy, Abidjan, Côte d'Ivoire

${ }^{4}$ Ministry of Health, Abidjan Côte d'Ivoire

\section{Correspondence to}

Dr Bea Vuylsteke, Institute of Tropical Medicine,

Nationalestraat 155, 2000

Antwerp, Belgium;

bvuylsteke@itg.be

Accepted 10 December 2011 Published Online First

11 February 2012

\begin{abstract}
Objectives To assess condom use and prevalence of sexually transmitted infections (STI) and HIV among male sex workers (MSW) in Abidjan, Côte d'lvoire.

Methods A cross-sectional survey was conducted between October 2007 and January 2008 among MSW attending a sex worker clinic in Abidjan. A short questionnaire was administered in a face-to-face interview, and the participants were asked to provide a urine sample for STI testing and to self-collect transudate of the gingival mucosa for anonymous HIV testing, using a rapid test. A rectal swab for STI testing was taken by a physician. Molecular amplification assays were performed for the detection of Chlamydia trachomatis, Neisseria gonorrhoeae and Trichomonas vaginalis.
\end{abstract}

Results 96 MSW participated in the survey, their median age was 27 years and the median duration of sex work was 5 years. Consistent condom use with clients during the last working day was $86.0 \%$, and consistent condom use with the regular partner during the last week was $81.6 \%$. HIV infection was detected in $50.0 \%$ of the participants. The prevalence of $N$ gonorrhoeae was $12.8 \%$, chlamydia infection was present in $3.2 \%$ and $T$ vaginalis in $2.1 \%$ of the study participants.

Conclusions HIV and STI rates found in this study confirm the high risk and vulnerability status of MSW in Côte d'Ivoire. There is a definite need for studies exploring risk and risk perceptions among MSW in more depth and for services tailored to their needs, including developing and validating simple algorithms for the diagnosis of STI in MSW and men who have sex with men.

\section{INTRODUCTION}

Sex workers and their clients are a critical group in the spread of HIV infection, in every region in the world. ${ }^{1}$ While not as numerous as female sex workers (FSW), some men and transgenders also sell sex, predominantly to men. Male sex workers (MSW) are neither visible nor easy to access, ${ }^{2}$ and only few studies have reported on their risk behaviour and/or rates of sexually transmitted infections (STIs) and HIV. One study from Mombasa, Kenya, has highlighted the high vulnerability of MSW to HIV infection, but to our knowledge, so far no data have been reported on HIV prevalence among MSW in sub-Saharan Africa. ${ }^{3}$ MSW combine two high-risk behaviours: as sex workers, they have multiple sexual partners and as men who have sex with men (MSM), they often have receptive anal intercourse. Furthermore, bisexual behaviour is common among MSW, and as such, they could act as a bridging population between heterosexual women and MSM/bisexual men. ${ }^{4}$

Côte d'Ivoire is one of the countries most severely affected by the HIV/AIDS epidemic in West Africa, with an estimated HIV prevalence in the adult population of $3.9 \%$ and a two-fold to fivefold higher prevalence in FSW. ${ }^{5} 6$

Most MSW in Abidjan are MSM and offer sexual services for financial gain. They are generally the passive partner, called 'woubi' who takes the role of 'wife' and have male clients.' 8 They are often street based and dressed as women, but an increasing number offer their services through the internet..$^{8}$ As in many African countries, MSM in Côte d'Ivoire suffer from stigmatisation and they frequently marry a woman in order to comply with the norms of society.

As part of a comprehensive monitoring and evaluation plan of the sex worker programme in Côte d'Ivoire, a facility-based survey was conducted in 2007 to assess condom use and prevalence of STIs and HIV among MSW in Abidjan.

\section{METHODS \\ Study setting}

In 1992, the Projet RETRO-CI of the Centers for Disease Control and Prevention (Atlanta, Georgia USA) in collaboration with the Ministry of Health of Côte d'Ivoire and the Institute of Tropical Medicine (ITM), Antwerp, Belgium, set up a dedicated clinic, the 'Clinique de Confiance' ('Confidence Clinic') for FSW in Abidjan. From 2004 up to 2010, the clinic was supported by Family Health International and the ITM, and received financial support from the President's Emergency Plan for AIDS Relief (PEPFAR) and the Belgian Directorate-General for Development Cooperation (DGDC). MSW have been seeking services at the 'Clinique de Confiance' since 2002 and specialised services for MSW were set up in 2004. A comprehensive package of prevention and care services is offered including behaviour change communication and condom promotion and distribution by and in collaboration with peer educators, STI screening and treatment, counselling and testing (CT) and care for the HIV infected. xhtm 


\section{Study procedures}

A cross-sectional survey was conducted between October 2007 and January 2008 among MSW attending the 'Clinique de Confiance' in Abidjan, Côte d'Ivoire. Sex workers were defined as men who provide sexual services in exchange for money, goods or other benefits. Study participants were at least 15 years old. All consecutive MSW attending the 'Clinique de Confiance' from
15 October 2007 until 30 January 2008 were invited to participate. Each man could participate only once in the study.

A research assistant checked the eligibility of the potential study participants and asked for written informed consent. A short questionnaire was administered in a face-to-face interview, which included questions on socio-demographic characteristics, sexual behaviour and condom use.

Table 1 Demographic and behavioural characteristics of male sex workers attending the Clinique de Confiance

\begin{tabular}{|c|c|c|c|c|}
\hline & $\begin{array}{l}\text { All visits, } \\
\mathrm{N}=96\end{array}$ & $\begin{array}{l}\text { First visits, } \\
\mathrm{N}=33\end{array}$ & $\begin{array}{l}\text { Repeat visits, } \\
\mathrm{N}=63\end{array}$ & p Value* \\
\hline Median age, years & 27 & 25 & 29 & 0.03 \\
\hline \multicolumn{5}{|l|}{ Country of origin (\%) } \\
\hline Côte d'lvoire & $89(92.7)$ & $29(87.9)$ & $60(95.2)$ & 0.19 \\
\hline Other (West Africa) & $7(7.3)$ & $4(12.1)$ & $3(4.8)$ & \\
\hline Attended school (\%) & $84(87.5)$ & $30(90.9)$ & $54(85.7)$ & 0.46 \\
\hline Regular partner $(\%)$ & $59(62.1)$ & $23(69.7)$ & $36(58.1)$ & 0.27 \\
\hline \multicolumn{5}{|l|}{ HIV test in the past (\%) } \\
\hline Never & $28(29.2)$ & $18(54.5)$ & $10(15.9)$ & $<0.001$ \\
\hline Once & $27(28.1)$ & $9(27.3)$ & $18(28.6)$ & \\
\hline Two times & $20(20.8)$ & $3(9.1)$ & $17(27.0)$ & \\
\hline At least three times & $21(21.9)$ & $3(9.1)$ & $18(28.6)$ & \\
\hline Knows his HIV status $(\%)$ & $62(64.6)$ & $14(42.4)$ & $62(76.2)$ & 0.001 \\
\hline Reason for attending the clinic & & & & $<0.001$ \\
\hline Check-up & $16(16.7)$ & $16(48.5)$ & $0(0.0)$ & \\
\hline Illness & $55(57.3)$ & $9(27.3)$ & $46(73.0)$ & \\
\hline Pick-up of medicine & $9(9.4)$ & $0(0.0)$ & $9(14.3)$ & \\
\hline Buying lubricant gel & $1(1.0)$ & $0(0.0)$ & $1(1.6)$ & \\
\hline HIV test & $3(3.1)$ & $0(0.0)$ & $3(4.8)$ & \\
\hline Others & $12(12.5)$ & $8(24.2)$ & $4(6.3)$ & \\
\hline Duration of sex work, years (\%) & & & & 0.02 \\
\hline$<3$ & $23(24.0)$ & $14(42.4)$ & $9(14.3)$ & \\
\hline $3-4$ & 18 (18.7) & $6(18.2)$ & $12(19.0)$ & \\
\hline $5-9$ & $26(27.1)$ & $6(18.2)$ & $20(31.7)$ & \\
\hline$\geq 10$ & $29(30.2)$ & $7(21.2)$ & $22(34.9)$ & \\
\hline Median duration of sex work, years & 5 & 3 & 6 & 0.004 \\
\hline $\begin{array}{l}\text { Median number of clients during } \\
\text { last working day }\end{array}$ & 1 & 1 & 1 & 0.54 \\
\hline Median price paid by last client, in CFA† & 6000 & 10000 & 5000 & 0.36 \\
\hline Use of lubricant gel (\%) & $69(71.9)$ & $18(54.5)$ & $51(80.9)$ & 0.006 \\
\hline Condom use with clients $(\%)$ & & & & 0.02 \\
\hline Always & $66(68.7)$ & $17(51.5)$ & $49(77.8)$ & \\
\hline Often & $22(22.9)$ & $12(36.4)$ & $10(15.9)$ & \\
\hline Sometimes & $6(6.2)$ & $4(12.1)$ & $2(3.2)$ & \\
\hline Never & $2(2.1)$ & $0(0.0)$ & $2(3.2)$ & \\
\hline $\begin{array}{l}\text { Consistent condom use with clients during } \\
\text { last working day }(\%) \neq\end{array}$ & $80(86.0)$ & $24(72.7)$ & $56(93.3)$ & 0.006 \\
\hline Condom use with regular partner§ $(\%)$ & & & & 0.47 \\
\hline Always & $35(59.3)$ & $13(56.5)$ & $22(61.1)$ & \\
\hline Often & $13(22.0)$ & $7(30.4)$ & $6(16.7)$ & \\
\hline Sometimes & $5(8.5)$ & $2(8.7)$ & $5(8.3)$ & \\
\hline Never & $6(10.2)$ & $1(4.3)$ & $5(13.9)$ & \\
\hline $\begin{array}{l}\text { Consistent condom use with partner during } \\
\text { last week } \S(\%)\end{array}$ & $31(81.6)$ & $11(78.6)$ & $20(83.3)$ & 0.71 \\
\hline STI symptoms in the previous 12 months (\%) & $55(57.3)$ & $17(51.5)$ & $55(60.3)$ & 0.41 \\
\hline \multicolumn{5}{|l|}{ Drug use, ever (\%) } \\
\hline None & $85(88.5)$ & $29(87.9)$ & $56(88.9)$ & 0.72 \\
\hline Injectable & $1(1.0)$ & $0(0.0)$ & $1(1.6)$ & \\
\hline Soft drugs & $10(10.4)$ & $4(12.1)$ & $6(9.5)$ & \\
\hline
\end{tabular}

*Pearson $\chi^{2}$ test for comparison of proportions between first and repeat visits, Kruskal-Wallis rank test for comparison of medians. †US $\$ 1=500$ West African Franc (franc CFA) (2007).

‡Defined as the proportion of FSW who always used condoms during the last working day (clients) or during the last week (regular partner).

$\S$ Only for MSW having a regular partner $(\mathrm{N}=59)$.

FSW, female sex workers; MSW, male sex workers; STI, sexually transmitted infections. 
After the interview, the participants were asked to provide a urine sample for STI testing.

They were also asked to self-collect transudate of the gingival mucosa with the collection device produced by OraSure Technologies Inc. (Bethlehem, Pennsylvania, USA) for anonymous testing for HIV infection. Participants who wanted to know their HIV status were referred to the HIV counselling and testing service at the clinic where rapid tests were used on a blood sample according to the national guidelines (Determine, TM HIV-1/2; Abbott Laboratories Dainabot Co, Tokyo, Japan, and GENIE II HIV-1/HIV-2; Bio-Rad, Marnes La Coquette, France).

Lastly, participants were referred to a physician who offered a check-up for STIs including a genital examination and the collection of a rectal swab. Pharyngeal swabs were not taken due to financial considerations. STI symptoms and signs that were detected during the examination were immediately treated according to the clinical protocols free of charge. All participants were given extra male condoms.

MSW who were found to be HIV positive at the testing service of the clinic were offered counselling and psychological support by trained counsellors. Blood was taken for CD4 count and they were assessed on their eligibility for antiretroviral treatment as per the national guidelines in Côte d'Ivoire. Men who needed to take treatment received it free of charge at the 'Clinique de Confiance'.

\section{Laboratory procedures}

The urine samples and the rectal swabs were kept at $-20^{\circ} \mathrm{C}$ in the local laboratory until transportation to the STI reference laboratory of the ITM in Antwerp, Belgium, where molecular amplification assays were performed for the detection of Chlamydia trachomatis, Neisseria gonorrhoeae and Trichomonas vaginalis. $C$ trachomatis and $N$ gonorhoeae were detected using the AMPLICOR Chlamydia trachomatis/Neisseria gonorrhoeae (CT/ NG) test (Roche Diagnostic Systems, Indianapolis, Indiana, USA), and samples testing positive were re-tested with the BD ProbeTec assay ET Chlamydia trachomatis (CT) and Neisseria gonorrhoeae (GC)-amplified DNA assay (Becton-Dickinson, Sparks, Maryland, USA). Procedures were performed according to the manufacturer's instructions. For the detection of $T$ vaginalis, the DNA was extracted using the NucliSens miniMAG
(BioMérieux, Boxtel, the Netherlands). DNA templates were amplified with the TVK3/7 primer pairs ${ }^{9}$ and positive results were confirmed using the IP1/IP2 primer pairs. ${ }^{10} 11$ Adequacy of the specimens and inhibition of the amplification assay were assessed by amplification of the $\beta 2$-microglobulin gene. Participants were considered to be infected with $C$ trachomatis, $N$ gonorrhoeae or $T$ vaginalis, if either the urine sample or the rectal swab was positive on two different molecular amplification assays or, in the case of $T$ vaginalis, using two different primer pairs.

The oral mucosa transudate was tested with the Oraquick HIV-1/2 Antibody Test (OraSure Technologies Inc.) at the laboratory of the 'Clinique de Confiance'.

\section{Data management and analysis}

Data were entered in Epi-Info 3.4.3 (Centers for Disease Control and Prevention). All statistical analyses were done using Intercooled Stata V.11.0 (Stata Corporation). Standard statistical tests were used for the descriptive analyses of the study population. Men who attended the clinic for the first time were compared with men who came for a repeat visit on their sociodemographic characteristics, sexual behaviour and prevalence of HIV and other STIs. Risk factors for HIV infection were explored. Factors that were associated with HIV infection at a significance level of 0.1 in bivariate analysis were entered in a multivariate logistic regression model.

\section{Ethical considerations}

All biological specimens and study forms, including questionnaires, were labelled with a study number unlinked to the participant's name or other identifiers. The study was approved by the National Ethical Committee of Côte d'Ivoire, the Institutional Review Board of the ITM and the Ethical Committee of the University Teaching Hospital of Antwerp in Belgium, as well as the Protection of Human Subjects Committee of Family Health International.

\section{RESULTS}

A total of 102 men were invited to participate in the study, 6 of whom were not eligible mainly because they had stopped sex work. All of the remaining 96 men accepted to be in the study. Socio-demographic and behavioural characteristics are shown in

Table 2 Prevalence of HIV and STI among male sex workers

\begin{tabular}{|c|c|c|c|c|c|c|}
\hline & \multicolumn{2}{|c|}{ All visits, $N=94$} & \multicolumn{2}{|c|}{ First visits, $N=32$} & \multicolumn{2}{|c|}{ Repeat visits, $N=62$} \\
\hline & $\bar{n}$ & $\%(95 \% \mathrm{CI})$ & $\mathbf{n}$ & $\%(95 \% \mathrm{CI})$ & $\bar{n}$ & $\%(95 \% \mathrm{CI})$ \\
\hline HIV $^{*}$ & 48 & $50.0(39.6$ to 60.4$)$ & 14 & $42.4(25.5$ to 60.8$)$ & 34 & $54.0(40.9$ to 66.6$)$ \\
\hline Neisseria gonorrhoeae (NG) & 12 & $12.8(5.9$ to 19.6$)$ & 5 & 15.6 (2.3 to 28.9$)$ & 7 & 11.3 (3.2 to 19.4$)$ \\
\hline Rectal swab only & 7 & $7.4(2.0$ to 12.8$)$ & 4 & 12.5 (0.4 to 24.6$)$ & 3 & $4.8(0$ to 10.3$)$ \\
\hline Urine only & 4 & $4.2(0.1$ to 8.4$)$ & 1 & $3.1(0$ to 9.4$)$ & 3 & $4.8(0$ to 10.3$)$ \\
\hline Rectal swab + urine & 1 & $1.1(0$ to 3.1$)$ & 0 & 0.0 & 1 & $1.6(0$ to 4.8$)$ \\
\hline Chlamydia trachomatis (CT) & 3 & $3.2(0$ to 6.8$)$ & 1 & $3.1(0$ to 9.4$)$ & 2 & $3.2(0$ to 7.7$)$ \\
\hline Rectal swab only & 1 & $1.1(0$ to 3.1$)$ & 0 & 0.0 & 1 & $1.6(0$ to 4.8$)$ \\
\hline Urine only & 1 & $1.1(0$ to 3.1$)$ & 0 & 0.0 & 1 & $1.6(0$ to 4.8$)$ \\
\hline Rectal swab + urine & 1 & $1.1(0$ to 3.1$)$ & 1 & $3.1(0$ to 9.4$)$ & 0 & 0.0 \\
\hline NG or CT & 14 & 14.9 (7.5 to 22.2$)$ & 6 & 18.7 (4.4 to 33.0 ) & 8 & 12.9 (4.3 to 21.5$)$ \\
\hline Trichomonas vaginalis (TV) & 2 & $2.1(0$ to 5.1$)$ & 0 & 0.0 & 2 & $3.2(0$ to 7.7$)$ \\
\hline Rectal swab only & 2 & $2.1(0$ to 5.1$)$ & 0 & 0.0 & 2 & $3.2(0$ to 7.7$)$ \\
\hline Urine only & 0 & 0.0 & 0 & 0.0 & 0 & 0.0 \\
\hline Rectal swab + urine & 0 & 0.0 & 0 & 0.0 & 0 & 0.0 \\
\hline STI (NG or CT or TV) & 16 & 17.0 (9.3 to 24.8$)$ & 6 & 18.7 (4.4 to 33.0$)$ & 10 & 16.1 (6.7 to 25.5$)$ \\
\hline
\end{tabular}

${ }^{*} \mathrm{~N}=96,33$ and 63 for all, first and routine visits, respectively.

STI, sexually transmitted infections. 
table 1 . The median age was 27 years, and MSW coming for the first time were younger than MSW coming for a repeat visit. More than half of the men (62.1\%) had a regular partner (man or woman), and median duration of sex work was 5 years. Reported condom use was high with $86.0 \%$ of the participants reporting they always use a condom with their clients and $81.6 \%$ reporting they always use a condom with their regular partner. STI symptoms in the previous 12 months (genital discharge, dysuria, ulcers or warts) were reported by $57.3 \%$ of the MSW. Only one MSW reported having injected drugs in the past.

More than half of the men coming for the first time had never been tested for HIV; however, $76.2 \%$ of the MSW who had attended the clinic before reported that they knew their HIV status.

HIV infection was detected in $50.0 \%$ of the participants, $42.4 \%$ among the men who attended the clinic for the first time and $54.0 \%$ among the men who came for a repeat visit $(p=0.28)$.

Table 3 Factors associated with HIV infection in bivariate and multivariate analyses

\begin{tabular}{|c|c|c|c|c|}
\hline & $\mathbf{N}$ & $\%$ HIV & $\begin{array}{l}\text { Bivariate } \\
\text { Crude OR (95\% Cl) }\end{array}$ & $\begin{array}{l}\text { Multivariate logistical } \\
\text { regression } \dagger \\
\text { Adjusted } \mathrm{OR}(95 \% \mathrm{Cl})\end{array}$ \\
\hline \multicolumn{5}{|l|}{ Age (years) } \\
\hline$<20$ & 12 & 33.3 & 1 & 1 \\
\hline $21-25$ & 26 & 42.3 & $1.47(0.34$ to 6.28$)$ & $1.05(0.19$ to 5.65$)$ \\
\hline $26-30$ & 29 & 44.8 & $1.62(0.39$ to 6.80$)$ & 0.66 (0.12 to 3.72$)$ \\
\hline$>30$ & 29 & 69.0 & 4.44 (0.95 to 20.7$)$ & 1.65 (0.29 to 9.34$)$ \\
\hline \multicolumn{5}{|c|}{ Country of origin } \\
\hline Côte d'Ivoire & 89 & 48.3 & 1 & - \\
\hline Other & 7 & 71.4 & $2.67(0.48$ to 14.83$)$ & - \\
\hline \multicolumn{5}{|l|}{ Went to school } \\
\hline Yes & 84 & 44.0 & 1 & 1 \\
\hline No & 12 & 91.7 & $13.97(1.52$ to 128.10$)$ & $12.57(1.43$ to 110.36$)$ \\
\hline \multicolumn{5}{|c|}{ First visit to SW centre } \\
\hline Yes & 33 & 42.4 & 1 & - \\
\hline No & 63 & 54.0 & 1.59 (0.67 to 3.76$)$ & - \\
\hline \multicolumn{5}{|c|}{ Duration of sex work } \\
\hline$<5$ years & 41 & 24.4 & 1 & 1 \\
\hline$\geq 5$ years & 55 & 69.1 & $6.93(2.49$ to 19.30$)$ & $6.73(2.34$ to 19.32$)$ \\
\hline \multicolumn{5}{|c|}{ Number of clients during last working day } \\
\hline $0-1$ & 67 & 53.7 & 1 & - \\
\hline $2+$ & 29 & 41.4 & $0.61(0.25$ to 1.48$)$ & - \\
\hline \multicolumn{5}{|c|}{ Price paid by last client (in CFA) } \\
\hline$\leq 5000$ & 44 & 47.7 & 1 & - \\
\hline$>5000$ & 43 & 48.8 & 1.04 (0.45 to 2.44$)$ & - \\
\hline \multicolumn{5}{|c|}{ Use of lubricant gel } \\
\hline Yes & 69 & 55.1 & 1 & - \\
\hline No & 27 & 37.0 & $0.48(0.19$ to 1.22$)$ & - \\
\hline \multicolumn{5}{|c|}{ Consistent condom use with clients during last working day } \\
\hline Yes & 80 & 50.0 & 1 & - \\
\hline No & 13 & 38.5 & $0.62(0.19$ to 2.10$)$ & - \\
\hline \multicolumn{5}{|c|}{ Consistent condom use with regular partner during last week } \\
\hline Yes & 31 & 45.2 & 1 & - \\
\hline No & 7 & 57.1 & 1.62 (0.30 to 8.73$)$ & - \\
\hline \multicolumn{5}{|c|}{ Has done a HIV test } \\
\hline Yes & 68 & 50.0 & 1 & - \\
\hline No & 28 & 50.0 & 1.00 (0.41 to 2.42$)$ & - \\
\hline \multicolumn{5}{|c|}{ Knows HIV status } \\
\hline Yes & 62 & 48.4 & 1 & - \\
\hline No & 34 & 52.9 & 1.20 (0.52 to 2.79$)$ & - \\
\hline \multicolumn{5}{|c|}{ Has had STI symptoms in the last 12 months } \\
\hline Yes & 55 & 47.3 & 1 & - \\
\hline No & 41 & 53.6 & 1.29 (0.57 to 2.92$)$ & - \\
\hline \multicolumn{5}{|c|}{ Trichomonas vaginalis infection } \\
\hline Yes & 2 & 100.0 & 1 & - \\
\hline No & 92 & 48.9 & - & - \\
\hline \multicolumn{5}{|l|}{$\mathrm{NG} / \mathrm{CT} \neq$} \\
\hline Yes & 14 & 42.9 & 1 & - \\
\hline No & 80 & 51.2 & $0.71(0.22$ to 2.26$)$ & - \\
\hline
\end{tabular}


The prevalence of $N$ gonorrhoeae was $12.8 \%$ for all participants and $15.6 \%$ among first-time attendees. $N$ gonorrhoeae was more frequently found in rectal swabs as compared with urine, although the difference did not reach statistical significance $(8.5 \%$ vs $5.3 \%, p=0.34)$. Chlamydia infection was present in $3.2 \%$ and $T$ vaginalis in $2.1 \%$ of the study participants. All urine samples were negative for $T$ vaginalis (table 2 ).

Risk factors for HIV and STIs were explored in bivariate and multivariate analyses. In bivariate analysis, HIV infection was associated with older age, not having attended school and longer duration of sex work. In multivariate analysis, however, only lack of school attendance and duration of sex work for 5 years or more remained independently associated with HIV infection (see table 3). STIs (NG or CT or TV) were associated with reporting of STI symptoms in the past 12 months and with never having done a HIV test but only in bivariate analysis.

\section{DISCUSSION}

This study was the first one to assess the prevalence of HIV infection and STIs among MSW in Côte d'Ivoire. The HIV prevalence of $50.0 \%$ found in this study stands in large contrast with the HIV prevalence in the general male population of $15-49$ years in Côte d'Ivoire, which was $2.9 \%$ in $2005 .{ }^{12}$ The HIV prevalence among MSW (50\%, CI 40\% to 60\%) was also higher than the HIV prevalence among FSW found in a similar study at the same site and time (40\%, CI 33\% to 46\%), although this difference did not reach statistical significance. ${ }^{6}$ HIV was associated with the duration of sex work, which is an indicator of the duration of risk taking. Men who had attended school were less likely to be HIV infected. Possible explanations for this association include more easy access to prevention messages by men with higher levels of education and greater assertiveness in negotiations about condom use. In general, the literacy level of MSW was rather high in this study and certainly higher than the literacy level of the general male population in Côte d'Ivoire (84\% vs 66\%). ${ }^{12}$

Our sample may be not representative for the population of MSW in general because clinic visits are more likely done by HIV-infected sex workers, introducing a bias towards higher HIV prevalence rates. This is particularly the case for repeat visits, as $14 \%$ of these men in our sample said that the reason for attending the clinic was to collect medicine. For men attending the clinic for the first time however, the main reasons for coming to the clinic were check-ups and wanting to discover the clinic.

$N$ gonorrhoeae was detected in $8.5 \%$ of the rectal swabs and in $5.3 \%$ of the urine samples. The rate of $N$ gonorrhoeae found in the urine is relatively high considering that MSW in Abidjan are known to usually engage in receptive anal intercourse. Unfortunately, we did not collect detailed data on sexual behaviour, so cannot be sure that they did not have insertive anal intercourse or intercourse with women. We did not take any oropharyngal swabs and it is thus likely that we have missed a number of infections. In Australia, urethral gonorrhoea was present in $2 \%$ of the MSM, as was pharyngeal gonorrhoea, but the prevalence of rectal gonorrhoea was slightly higher. ${ }^{13}$ Due to the lack of studies, we could not compare our results with African MSM.

Chlamydia prevalence was $3 \%$. We tested the stored left-over aliquots of the two $C$ trachomatis-positive specimens using the real-time-PCR, and both specimens did not belong to the $C$ trachomatis L. genotypes, which are causing Lymphogranuloma venereum (LGV) (results not shown).

We found a rather low prevalence of $T$ vaginalis among MSW in Abidjan compared with FSW in a similar study (13\%) or with heterosexual men in two studies in Tanzania (11\% in Mwanza and $10 \%$ in Moshi). ${ }^{6} 1415$ In only two men, $T$ vaginalis was found in rectal samples. This low prevalence in the rectal samples is not surprising. In a study among MSM in San Francisco, only 3 of 500 rectal samples were positive for $T$ vaginalis with Transcription Mediated Amplification assay. ${ }^{16} T$ vaginalis probably does not thrive in the rectum and as a result is not often found in men who have sex only with men. ${ }^{17}$ Furthermore, $T$ vaginalis was not detected in the urine samples of our study population. It is possible that we missed a few cases due to a less than optimal sensitivity of PCR on urine. It has previously been described that PCR for $T$ vaginalis on urine does not always perform well. ${ }^{18}$

Since the questionnaire did not include detailed questions on sexual behaviour, we do not know whether the absence of sex with women may play a role in the rates of different STI found in this population. Future studies among MSW should explore their sexual behaviour with men and women in more detail.

The DNA amplification for the detection of STIs was performed in Antwerp since these techniques were not available in Côte d'Ivoire at that time. However, even if PCR tests are available in reference centres, they are too complicated and expensive for widespread use and routine diagnostics in a setting such as Côte d'Ivoire. In low-resource countries, a more realistic and simple approach is needed for the screening and diagnosis of STI. The syndromic approach has been adapted and validated for the diagnosis of symptomatic STI in FSW in many settings. ${ }^{19-21}$ For MSW and MSM however, algorithms for urethral infections were for a long time the only tools available. The recent WHO guidelines for the prevention and treatment of HIV and other STI among MSM and transgender people propose diagnostic algorithms for STI, including rectal STI, for which no validation has been done. ${ }^{22}$ Our results show the need for developing and validating algorithms for the diagnosis of urethral and rectal STI in MSM and MSW. In addition, simple and rapid point of care tests are urgently needed, and research for these tests should be a public health priority.

In this study, $69 \%$ of MSW reported always using a condom with their clients. The proportion of MSW who reported always using a condom with their regular partners was somewhat less, $59 \%$. This is in contrast to the study we conducted with FSW in Abidjan where $81 \%$ reported always using a condom with their clients and only $25 \%$ with their regular partners. The level of intimacy and emotional ties with the sexual partner regardless of assessed risk seems an important factor for condom use. ${ }^{6} 2324$ More research is needed to better understand condom use and barriers to condom use among MSW.

\section{Key messages}

- Male sex workers (MSW) are at high risk for sexually transmitted infections (STI) and HIV in Côte d'Ivoire, with $50 \%$ of them infected with HIV and $13 \%$ with Neisseria gonorrhoeae.

- Condom use is relatively high among MSW; however, more studies are needed to explore risk and risk perceptions among MSW in more depth.

- There is an urgent need for the development of simple and rapid point of care tests for the diagnosis of STI in MSW and MSM.

- There is a need for tailored services and simple STI algorithms for MSM and MSW. 
In conclusion, HIV and STI rates found in this study confirm the high risk and vulnerability status of MSW in Côte d'Ivoire. There is a definite need for more studies exploring risk and risk perceptions among MSW in more depth, including the risk taking with different types of clients and with other male and female partners. There is also a need for developing and validating simple and rapid point of care tests in addition to specific algorithms for the diagnosis of STI in MSW and MSM. Finally, better understanding of the needs and size of this target population will contribute to the provision of adapted low-threshold services, including the promotion of condoms and lubricant gel, STI diagnosis and treatment, as well as HIV testing and treatment for the infected.

Contributors BV: protocol development, supervision of the study procedures and writing of the manuscript; GS: protocol development and writing of the manuscript; LS: training research assistants, field supervision, local data management and analysis and writing of the manuscript; TC: supervision and quality control of the laboratory procedures in Antwerp and writing of the manuscript; VE-T: protocol development and writing of the manuscript; $A B$ : general supervision and writing of the manuscript and $\mathrm{ML}$ : general supervision and writing of the manuscript.

Funding Belgian Directorate-General for Development Cooperation.

Competing interests None.

Ethics approval National Ethical Committee of Côte d'Ivoire; the Institutional Review Board of the Institute of Tropical Medicine and the Ethical Committee of the University Teaching Hospital of Antwerp in Belgium and the Protection of Human Subjects Committee of Family Health International.

Provenance and peer review Not commissioned; externally peer reviewed.

\section{REFERENCES}

1. Vuylsteke B, Das A, Dallabetta G, et al. In: Mayer K, Pizer HF, eds. HIV Prevention: Preventing HIV Among Sex Workers. Academic Press, 2008:376-406.

2. Belza MJ. Risk of HIV infection among male sex workers in Spain. Sex Transm Infect 2005:81:85-8.

3. Okal J, Luchters $S$, Geibel S, et al. Social context, sexual risk perceptions and stigma: HIV vulnerability among male sex workers in Mombasa, Kenya. Cult Health Sex 2009;11:811-26.

4. Morse EV, Simon PM, Osofsky HJ, et al. The male street prostitute: a vector for transmission of HIV infection into the heterosexual world. Soc Sci Med 1991;32:535-9.

5. UNAIDS. Epidemiological Fact Sheet, Sub Saharan Africa. Geneva: UNAIDS, 2009. http://data.unaids.org/pub/FactSheet/2009/20091124 FS SSA en.pdf

6. Vuylsteke B, Sika L, Semdé G, et al. HIV/STI prevalence and risk behaviour among female and male sex workers attending three prevention and care services in Côte d'Ivoire. Proceedings of the 18th International Society for STD Research Conference ISSTDR. London, UK. International Society for STD Research, 2009. Abstract P. 3.162 .
7. Migraine-George T. Beyond the "internalist" vs "externalist" debate: the localglobal identities of African homosexuals in two films, "Woubi Chéri" and "Dakan". J Afr Cult Stud 2003;16:45-56.

8. Bamba A. Regard sur les liens entre pratiques homosexuelles et lutte contre les IST/ VIH/Sida en Côte d'lvoire. Mémoire présenté pour l'obtention du Master en Développement de l'Université Senghor. Alexandrie, Egypte, 2010.

9. Kengne P, Veas F, Vidal N, et al. Trichomonas vaginalis: repeated DNA target for highly sensitive and specific polymerase chain reaction diagnosis. Cell Mol Biol (Noisy-le-grand) 1994;40:819-31.

10. Shaio MF, Lin PR, Liu JY. Colorimetric one-tube nested PCR for detection of Trichomonas vaginalis in vaginal discharge. J Clin Microbiol 1997;35:132-8.

11. Crucitti T, Van Dyck E, Tehe A, et al. Comparison of culture and different PCR assays for detection of Trichomonas vaginalis in self collected vaginal swab specimens. Sex Transm Infect 2003;79:393-8.

12. Institut National de la Statistique (INS) et Ministère de la Lutte contre le Sida [Côte d'Ivoire] et ORC Macro. Enquête sur les Indicateurs du Sida, Côte $d^{\prime}$ Ivoire 2005. Calverton, Maryland, USA: INS et ORC Macro, 2006.

13. Ryder N, Bourne C, Donovan B. Different trends for different sexually transmissible infections despite increased testing of men who have sex with men. Int J STD AIDS 2011;22:335-7.

14. Vuylsteke B, Das A, Dallabetta G, et al. Preventing HIV among sex workers. In: Mayer $\mathrm{KH}$, Pizer HF, eds. HIV prevention. A comprehensive approach. Academic Press, 2009.

15. Klinger EV, Kapiga SH, Sam NE, et al. A Community-based study of risk factors for Trichomonas vaginalis infection among women and their male partners in Moshi urban district, northern Tanzania. Sex Transm Dis 2006;33:712-18.

16. Francis SC, Kent CK, Klausner JD, et al. Prevalence of rectal Trichomonas vaginalis and Mycoplasma genitalium in male patients at the San Francisco STD clinic, 20052006. Sex Transm Dis 2008;35:797-800.

17. Martin DH, Rein M. Trichomonas vaginalis. In: Mandell G, Bennet J, Dolin R, eds Principles and Practice of Infectious Diseases. New York: Elsevier/Churchill Livingstone, 2005

18. Kaydos SC, Swygard H, Wise SL, et al. Development and validation of a PCR-based enzyme-linked immunosorbent assay with urine for use in clinical research settings to detect trichomonas vaginalis in women. J Clin Microbiol 2002;40:89-95.

19. Vuylsteke B, Laga M, Alary $M$, et al. Clinical algorithms to screen women for gonococcal and chlamydial infection: evaluation for pregnant women and prostitutes in Zaire. Clin Infect Dis 1993;17:82-8.

20. Diallo MO, Ghys P, Vuylsteke B, et al. Evaluation of simple diagnostic algorithms for Neisseria gonorrhoeae and Chlamydia trachomatis cervical infections in female sex workers in Abidjan, Côte d'lvoire. Sex Transm Inf 1998;74(Suppl 1):S106-11.

21. Germain $\mathbf{M}$, Alary $\mathbf{M}$, Guèdèmè $\mathrm{A}$, et al. Evaluation of a screening algorithm for the diagnosis of genital infections with Neisseria gonorrhoeae and Chlamydia trachomatis among female sex workers in Bénin. Sex Transm Dis 1997;24:109-15.

22. WHO. In: World Health Organization, Department of HIV/AIDS, eds. Guidelines: Prevention and Treatment of HIV and Other Sexually Transmitted Infections Among Men Who Have Sex With Men and Transgender People. Recommendations for a Public Health Approach. Geneva: WHO, 2011. http://whqlibdoc.who.int/ publications/2011/9789241501750 eng.pdf

23. Nguyen VT, Nguyen $\mathrm{TL}$, Nguyen $\overline{\mathrm{D}} \mathrm{H}$, et al. Sexually transmitted infections in female sex workers in five border provinces of Vietnam. Sex Transm Dis 2005:32:550-6.

24. Pickering $\mathbf{H}$, Quigley $\mathrm{M}$, Hayes RJ, et al. Determinants of condom use in 24,000 prostitute/client contacts in The Gambia. AIDS 1993;7:1093-8. 